Article

\title{
Reliability Analysis of Intersection Sight Distance at Roundabouts
}

\author{
Said M. Easa ${ }^{1, *(\mathbb{D}}$, Yang Ma ${ }^{2} \mathbb{D}$, Shixu Liu ${ }^{3}$, Yanqun Yang ${ }^{3}$ and Shriniwas Arkatkar ${ }^{4}$ \\ 1 Department of Civil Engineering; Ryerson University, 350 Victoria Street, Toronto, ON M5B 2K3, Canada \\ 2 School of Transportation, Southeast University, 2 Dongnandaxue Rd, Nanjing 211189, China; \\ mayang93@seu.edu.cn \\ 3 College of Civil Engineering, Fuzhou University, Fuzhou 350108, China; liushixu@fzu.edu.cn (S.L.); \\ yangyanqun@fzu.edu.cn (Y.Y.) \\ 4 Civil Engineering Department, Sardar Vallabhbhai National Institute of Technology, Surat 395007, India; \\ sarkatkar@ced.svnit.ac.in \\ * Correspondence: seasa@ryerson.ca; Tel.: +1-416-979-5000 (ext. 7868)
}

Received: 18 July 2020; Accepted: 4 August 2020; Published: 6 August 2020

\begin{abstract}
This paper presents a reliability-based method for the design of intersection sight distance (ISD) at traffic roundabouts using the linear and nonlinear deceleration profiles of the entry vehicles. The reliability method is based on the first-order second moment method which is simple and relatively accurate compared with advanced methods. The nonlinear deceleration profile includes a shape parameter that produces the linear profile as a special case. Deterministic and reliability-based formulas for the required ISD for an approaching vehicle are developed for the entry vehicle on the left and the vehicle on the circulating roadway. Then, the design values of the ISD legs, applicable to any type of roundabout, are presented for different probabilities of non-compliance $\left(P_{n c}\right)$ and different coefficients of variations. For the special case of single-lane symmetrical roundabouts, which have a well-defined geometry, the lateral clearance needs are established. The sensitivity analysis shows that ISD is very sensitive to both the mean and variance of the critical headway. The results show that the deterministic method results in ISD values that correspond to a very small $P_{n c}$, indicating that the method is very conservative. The proposed method, which provides flexibility in selecting ISD for any given $P_{n c}$, should be of interest to highway designers and practitioners to promote roundabout safety.
\end{abstract}

Keywords: roundabouts; intersection sight distance; reliability; first-order second-moment; lateral clearance; design aids

\section{Introduction}

Intersection sight distance (ISD) plays a crucial role in the design of roundabouts. Adequate ISD is required for a driver at each entry of the roundabout to identify safe gaps from conflicting traffic streams. More specifically, ISD should be checked at two locations of the approach vehicle at each entry: (1) a certain distance before the crosswalk and (2) a stationary vehicle at the yield line. Drivers at these locations should clearly see the two conflicting vehicles: circulating and entering from the immediate left. The current methods for calculating ISD are deterministic. Such methods are presented in the roundabout information and design guides by Rodegerdts et al. [1]; the Transportation Association of Canada [2]; the American Association of State Highway and Transportation Officials (AASHTO) [3]; the Federal Highway Administration (FHWA) [4]; the Government of Queensland (GQ) [5]; and the Department for Regional Development, Northern Ireland (DRDNI) [6]. However, the ISD design parameters, such as design speeds, deceleration rate, and critical headway for the conflicting vehicles are random variables in nature instead of fixed values, and they may be correlated with one another. 
It has been recognized in the highway engineering field that the reliability-based approach to geometric design can accommodate the uncertainties in the design variables and thus can help improve the overall safety of highways. In the reliability-based (probabilistic) approaches, a safety margin is defined as the difference between the supplied and demanded values of the design element. A negative value of the safety margin would indicate a risk of failure or non-compliance; see Melchers and Beck [7].

Given the flexibility of reliability-based methods, they have been widely used to improve sight distance (SD) design. Table 1 presents a summary of previous reliability-based applications on sight distance and related highway geometric design elements. Examples include general geometric design elements by Navin [8], intergreen intervals at traffic signals by Easa [9], ISD for railway crossings by Easa [10], uncontrolled intersections by Easa [11], freeway entrance speed-change lanes by Fatema and Hassan [12] and Hassan et al. [13], highway cross sections by Ibrahim et al. [14], highway geometric design by Ismail and Sayed [15], truck escape ramps by Greto and Easa [16], and pedestrian green intervals by Easa and Cheng [17]. Most methods have used the first-order second-moment method (FOSM) of reliability analysis, including stop-controlled intersections by Easa and Hussain [18] and left turn at signalized intersections by Hussain and Easa [19]. Other methods have used the advanced version of FOSM (AFOSM) $[10,16]$. The more advanced first-order method (FORM) has been used by several authors, including Osama et al. [20], Richl and Sayed [21], De Santos-Berbe et al. [22], and Llorca et al. [23]. In addition, some researchers have used Monte Carlo (MC) simulation, such as El-Khoury and Hobeika [24] who studied passing sight distance (PSD) on two-lane highways; Sarhan and Hassan [25], who studied sight distance on three-dimensional highway alignments; Wood and Donnell [26], who studied sight distance on horizontal curves; and Andrade-Catano et al. [27], who studies headlight sight distance on sag vertical curves. MC simulation has also been used in some studies to verify the assumptions of the analytical reliability methods [17].

From Table 1, it is noted that many efforts in the literature have focused on the SD along highways and at intersections. Only a few studies have focused on SD design at roundabouts, such as Faizi and Easa [28]. In this paper, the authors proposed a reliability-based approach for optimizing the deterministic stopping sight distance (SSD) model recommended by AASHTO [3]. The stopping sight distance at three locations was addressed-roundabout approach, circulatory roadway, and roundabout exit—while the ISD was not considered. Therefore, a comprehensive probabilistic approach for the design of ISD at roundabouts is currently lacking. To address this knowledge gap, the objectives of this paper are fourfold: (1) to develop a reliability-based method for the design of ISD at roundabouts, (2) to formulate a nonlinear deceleration profile for the entry vehicles at roundabouts for ISD, (3) to develop reliability-based ISD design values that are applicable to any type of roundabout, and (4) to develop lateral clearance needs for the special case of single-lane symmetrical roundabouts.

Table 1. Summary of existing reliability-based studies related to sight distance.

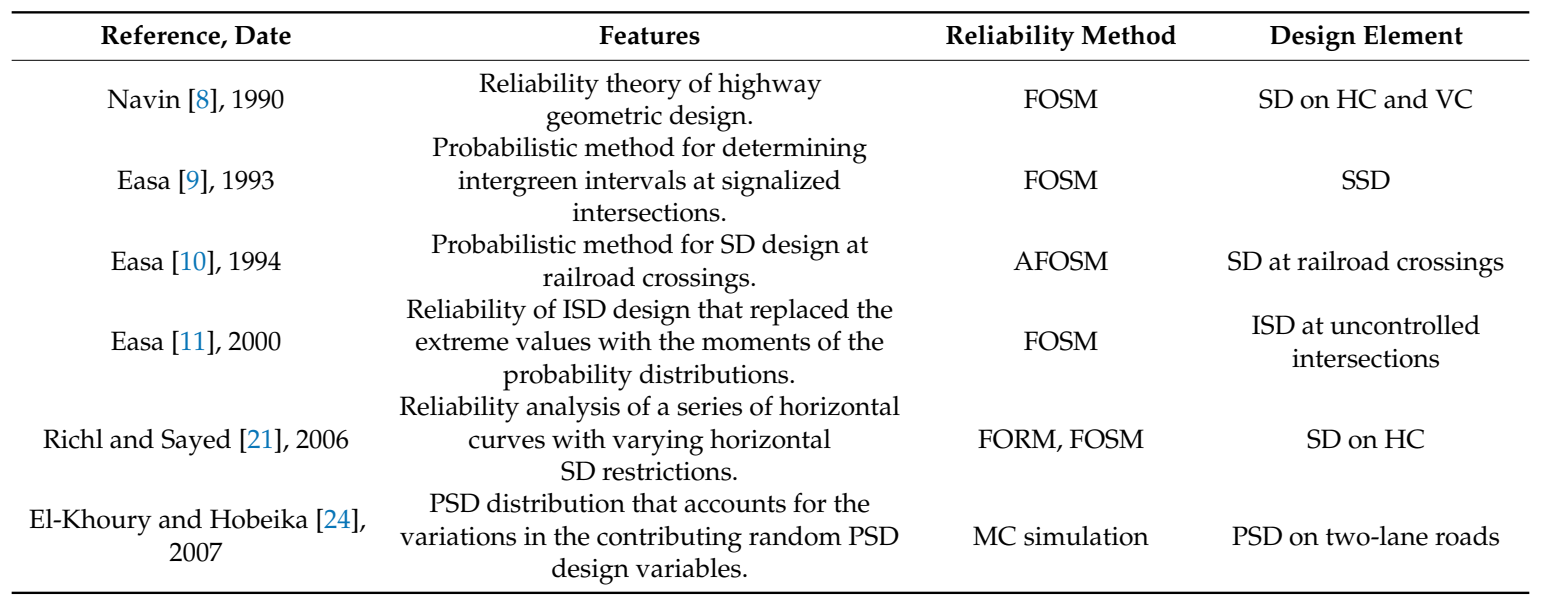


Table 1. Cont.

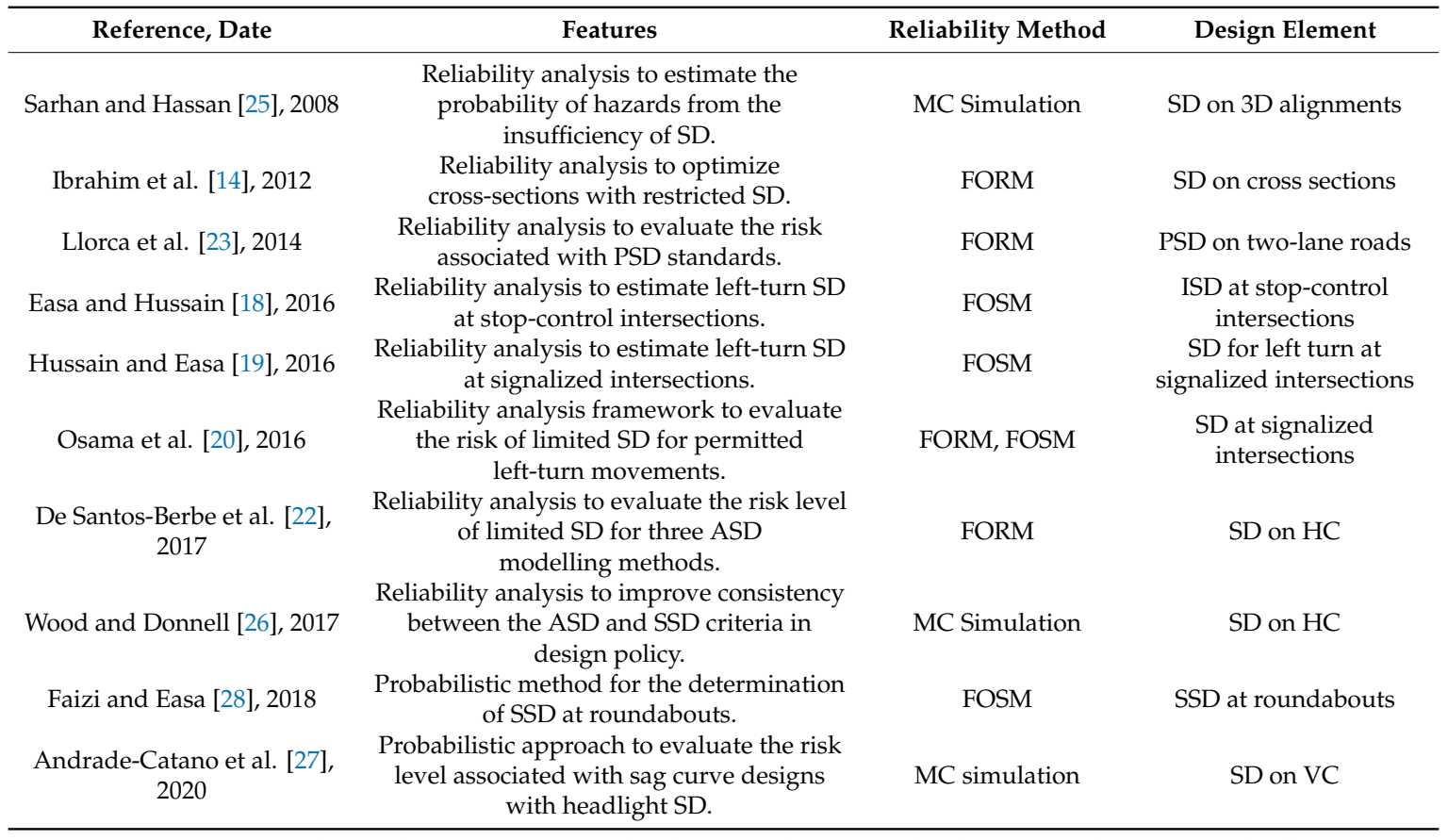

Note: SSD, DSD, and PSD denote stopping sight distance, decision sight distance, and passing sight distance, respectively; HC denotes horizontal curve; VC denotes vertical curve; and MC denotes Monte Carlo.

\section{Deterministic ISD with Nonlinear Deceleration}

\subsection{Modeling Nonlinear Deceleration Profile}

The deceleration profiles are formulated for the entry vehicles which decelerate from the entry speed $v_{e}$ to the circulating speed $v_{c}$. The analysis concept is based on a comparison of the kinematic equations associated with the deceleration rate. The concept is like that given by Wortman and Fox [29], who developed the deceleration profiles for stopping vehicles $\left(v_{c}=0\right)$. The stopping deceleration profile is a special case of the presented general formulation of deceleration profiles. Let the deceleration distance and deceleration time be denoted by $d$ and $t$, respectively. Three basic equations are used to calculate the deceleration rate, where each equation is a function of two of the variables $\left(v_{e}, v_{c}, d\right.$, and $t$ ), as follows:

$$
\begin{gathered}
a_{1}=\frac{v_{e}^{2}-v_{c}^{2}}{2 d}, \\
a_{2}=\frac{2\left(d-v_{c} t\right)}{t^{2}}, \\
a_{3}=\frac{v_{e}-v_{c}}{t},
\end{gathered}
$$

where $a_{1}, a_{2}$, and $a_{3}$ denote the deceleration rate $\left(\mathrm{m} / \mathrm{s}^{2}\right)$ that corresponds to Equations (1)-(3), respectively; $v_{e}$ and $v_{\mathcal{C}}$ denote the entry and circulatory speeds $(\mathrm{m} / \mathrm{s}) ; d$ denotes the deceleration distance $(\mathrm{m})$; and $t$ denotes the deceleration time (s).

Note that, to simplify the presented formulas, the speeds are in $\mathrm{m} / \mathrm{s}$, but the design aids presented later will make appropriate conversion of these speeds to $\mathrm{km} / \mathrm{h}$. For linear deceleration, $a_{1}=a_{2}=$ $a_{3}$. For nonlinear deceleration, however, the deceleration rates of Equations (1)-(3) will be different. The different cases of the deceleration profiles are quantified as follows:

$$
r=\frac{a_{1}}{a_{2}}
$$


where $r$ denotes the deceleration shape parameter. The deceleration rates $a_{1}$ and $a_{2}$ are used because for nonlinear deceleration profiles they represent limiting values, where $a_{3}$ always lies between them. That is, there are two possible inequalities $a_{1}<a_{3}<a_{2}$ and $a_{2}<a_{3}<a_{1}$, which correspond to $r<1$ and $r$ $>1$, respectively. For linear deceleration profiles, $r=1$.

The three possible deceleration profiles are shown in Figure 1. The time axis is the elapsed time from the start of the deceleration. The speed axis identifies the speed of the vehicle. The area under the curve is the distance over which the deceleration occurs. The slope of the curve at any point is the deceleration rate. Figure 1a represents linear deceleration $(r=1)$, and the area under the curve is $d_{1}$. Figure $1 \mathrm{~b}, \mathrm{c}$ represent the nonlinear deceleration rate when $r<1$ and $r>1$, respectively, with the corresponding areas $d_{2}$ and $d_{3}\left(d_{2}>d_{1}>d_{3}\right)$. Note that the deceleration profile of Figure $1 \mathrm{~b}$ starts with a gentle deceleration rate followed by a more aggressive rate, covering a larger distance (during the same time $t$ ) than that of linear decelerate rate. This behavior would be expected at a low entry speed with a large circulatory speed. On the other hand, the deceleration profile of Figure $1 \mathrm{c}$ starts with a more aggressive rate followed by a gentler rate, covering a smaller distance (during the same time $t$ ) than that of the linear decelerate rate. This behavior is expected at a high entry speed with a low circulatory speed.

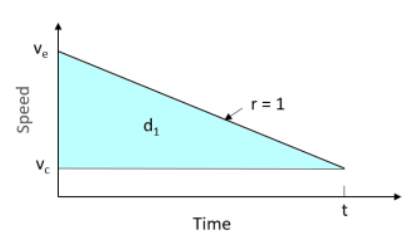

(a) Linear $(r=1)$.

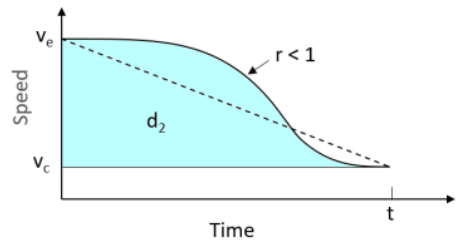

(b) Nonlinear $(r<1)$.

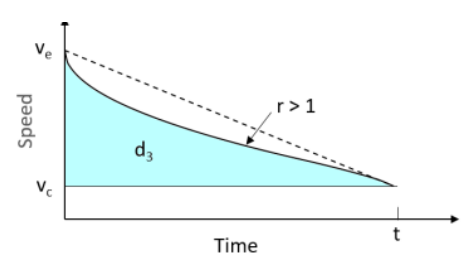

(c) Nonlinear $(r>1)$.

Figure 1. Illustration of linear and nonlinear deceleration profiles. (a) Linear $(r=1)$; (b) Nonlinear $(r<1)$; (c) Nonlinear $(r>1)$.

The distance travelled for each deceleration profile is needed for calculating the sight distance leg of ISD to the entry vehicle. To derive this distance, substituting $a_{1}$ and $a_{2}$ into Equation (4), then:

$$
r=\frac{t^{2}\left(v_{e}^{2}-v_{c}^{2}\right)}{4 d\left(d-v_{c} t\right)}
$$

where, based on Equation (3), $t$ is given by:

$$
t=\frac{v_{e}-v_{c}}{a}
$$

As noted, Equation (5) is a quadratic function in $d$. Solving this equation yields:

$$
d=\frac{r v_{c} t+t \sqrt{r^{2} v_{c}^{2}+r\left(v_{e}^{2}-v_{c}^{2}\right)}}{2 r},(r>0) .
$$

For linear deceleration $(r=1)$, Equation (7) gives:

$$
d=\frac{v_{e}^{2}-v_{c}^{2}}{2 a},(r=1)
$$

This is the well-known formula for the distance travelled during linear deceleration.

\subsection{Formulas for Sight Distance Legs}

The ISD is checked at each entry of the roundabout, generally at two locations of the approach (Figure 2): at a specified minimum distance from the yield line (typically $L_{\min }=15 \mathrm{~m}$ ) and at the yield 
line. At each entry, the sight distance triangle has two conflicting approaches that must be checked independently: (1) conflicting vehicles within the circulatory roadway (left-turn movements from the opposing entry approach) and (2) conflicting vehicles from the immediate upstream entry (left-turn or through movements).

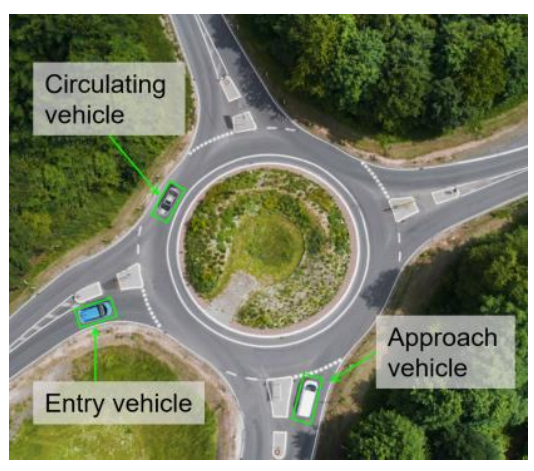

(a) Approach and conflicting vehicles.

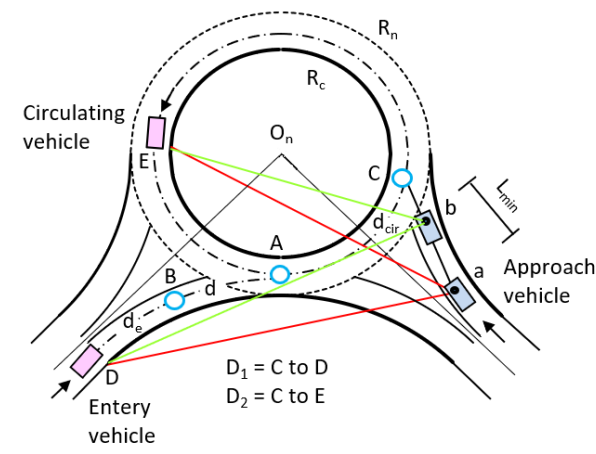

(b) Geometry of intersection sight distance (ISD).

Figure 2. Illustration of the intersection sight distance. (a) Approach and conflicting vehicles.

(b) Geometry of intersection sight distance (ISD).

A sight distance triangle that allows a driver to see and safely react to the conflicting vehicles is established. This triangle has three sides: the approach leg, the conflicting vehicle leg, and a line connecting these two limits (sightline). The approach leg (line from the driver's eye to the conflict point) is the same for both conflicting streams. For example, for an approach vehicle at $L_{\min }$ from the yield line, the approach leg is aC. For the conflicting-entry vehicle, the conflicting leg is $\mathrm{CD}$ (or $D_{1}$ ) and the third leg is the sightline $a D$. For the conflicting-circulating vehicle, the approach leg is $b C$, the conflicting leg is $\mathrm{CE}$ (or $D_{2}$ ), and the third leg is the sightline bE. The conflicting leg of the sight triangle should follow the conflicting-vehicle curved path; see Rodegerdts et al. [1,30,31].

In general, the sight distance leg of the entry vehicle (distance from the conflict point to the entry vehicle), $D_{1}$, is given by (Figure $2 b$ ):

$$
D_{1}=d_{c i r}+d+d_{e}
$$

where $d_{\text {cir }}$ denotes the distance along the circulatory part of the path; $d$ denotes the distance during deceleration, given by Equation (7); and $d_{e}$ denotes the distance along the entry curve. The distance $d_{e}$ equals the entry speed $v_{e}$ multiplied by the time $t_{e}$, which corresponds to $d_{e}$.

Note that $d_{c i r}$ depends on the minimum radius of the circulatory roadway $R$ (which depends on $v_{c}$ ), and the central angle $\theta$ suspended by this portion of the path (assumed to be $30^{\circ}$, based on the visual inspection of numerous roundabouts). The minimum radius was calculated based on the lateral friction coefficients for urban low speeds and $\mathrm{e}=0.02$ [3]. For the reliability analysis, based on AASHTO data, the relation between $R$ and $v_{c}$ was established using regression analysis as:

$$
R=0.0838 v_{c}^{2.661}
$$

where $R$ = the radius of the circulatory roadway $(\mathrm{m})$ and $v_{c}=$ the design speed of the circulatory roadway $(\mathrm{m} / \mathrm{s})$. Then, the portion of the entry vehicle path on the circulatory roadway, which equals $R \theta$ (where the angle is in radians), is given by:

$$
d_{c i r}=0.0439 v_{c}^{2.661} \text {. }
$$

The time spent by the entry vehicle on the circulatory roadway $t_{c i r}$ equals $d_{c i r} / v_{c}$. Thus,

$$
t_{c i r}=0.0439 v_{c}^{1.661} .
$$


There are three possible cases for calculating $D_{1}$, as shown in Figure 3. The three cases are formulated as follows:

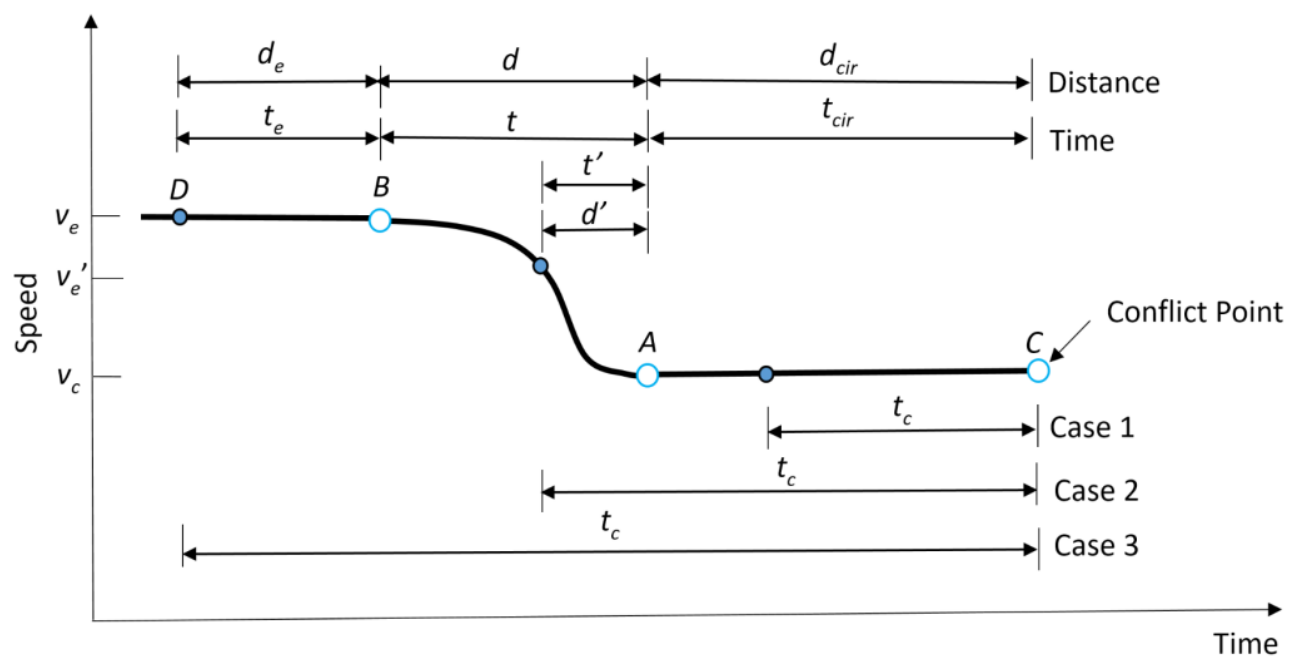

Figure 3. Geometry of the three cases for calculating $D_{1}$. Note: $C$ is the conflict point, $C A$ is the distance along the circulatory roadway, $\mathrm{AB}$ is the deceleration distance, and $\mathrm{BD}$ is the distance along the entry approach (see Figure 2b).

Case 1: The end of the sight distance leg lies on the circulatory part of the entry path. In this case, the critical headway is less than or equal to the time spent on the circulatory portion of the entry vehicle path $\left(t_{c} \leq t_{c i r}\right)$. In this case, $D_{1}$ is given by:

$$
D_{1}=t_{c} v_{c}, t_{c} \leq t_{c i r}(\text { Case } 1) .
$$

Case 2: The end of the sight distance leg lies on the deceleration part of the entry path. In this case, the critical headway greater than the time on the circulatory part but is less than the sum of the times on the circulatory and the deceleration parts $\left(t_{c i r}<t_{c}<t_{c i r}+t\right)$. To calculate $D_{1}$ in this case, let the time corresponding to the part on the deceleration profile be denoted as $t^{\prime}$ and the corresponding speed of the entry vehicle at the end of $D_{1}$ be $v_{e}^{\prime}$. Then,

$$
t^{\prime}=t_{c}-t_{c i r}=\frac{v_{e}^{\prime}-v_{c}}{a} .
$$

Based on Equation (14), $v_{e}^{\prime}$ is given by:

$$
v_{e}^{\prime}=a\left(t_{c}-t_{c i r}\right)+v_{c} .
$$

Then, $D_{1}$ can be derived as:

$$
D_{1}=d_{c i r}+\frac{r v_{c} t^{\prime}+t \prime \sqrt{r^{2} v_{c}^{2}+r\left(v_{e}^{\prime 2}-v_{c}^{2}\right)}}{2 r},(\text { Case 2), }
$$

where the second part of Equation (16) is the part of $D_{1}$ on the deceleration profile $\left(d^{\prime}\right)$.

Case 3: The end of the sight distance leg lies on the entry part before deceleration. In this case, the critical headway is greater than the sum of the times on the circulatory and deceleration parts 
$\left(t_{c} \geq t_{c i r}+t\right)$. The time on the entry part equals the critical headway time $t_{c}$ minus the time spent on the deceleration and the circulatory parts. Thus, $D_{1}$ can be derived as:

$$
D_{1}=\frac{r v_{c} t+t \sqrt{r^{2} v_{c}^{2}+r\left(v_{e}^{2}-v_{c}^{2}\right)}}{2 r}+v_{e} t_{c}-\frac{v_{e}\left(v_{e}-v_{c}\right)}{a}+d_{c i r}\left(1-\frac{v_{e}}{v_{c}}\right), \quad \text { (Case 3). }
$$

Note that for $r=1$ (linear deceleration), Equation (17) becomes:

$$
D_{1}=-\frac{\left(v_{e}-v_{c}\right)^{2}}{2 a}+v_{e} t_{c}+d_{c i r}\left(1-\frac{v_{e}}{v_{c}}\right) .
$$

This is the deterministic formula of $D_{1}$ for the linear deceleration rates.

For the circulating vehicle, the length of the conflicting leg is given by:

$$
D_{2}=t_{c} v_{c}
$$

where $D_{2}$ denotes the length of the sight distance leg for the conflicting circulating vehicle $(\mathrm{m}), t_{c}=$ the critical headway for entering the roundabout (s), and $v_{c}=$ the design speed of the conflicting circulating vehicle $(\mathrm{km} / \mathrm{h})$. Note that Equation (20) is equivalent to the sight distance leg for the entry vehicle of Case 2.

The effect of the deceleration shape parameter on the sight distance $D_{1}$ was calculated for different values of $r(0.5,1$, and 1.5) for the deterministic case. Different combinations of entry speed $\left(V_{e}=30 \mathrm{~km} / \mathrm{h}\right.$ to $\left.70 \mathrm{~km} / \mathrm{h}\right)$ and circulatory speed $\left(V_{c}=20 \mathrm{~km} / \mathrm{h}\right.$ to $\left.60 \mathrm{~km} / \mathrm{h}\right)$ and the 90 th percentile value of $t_{c}$ and the 10th percentile value of $a$ were used. The results are presented in Table 2. As noted, for $r=0.5$ the difference in $D_{1}$ between the linear and nonlinear profiles reaches up to $19.3 \%$, and for $r=1.5$ the difference reaches up to $-8.1 \%$. Obviously, when $V_{e}=V_{c}$, there is no deceleration, and the

\begin{tabular}{|c|c|c|c|c|c|c|c|c|}
\hline \multirow{4}{*}{$\begin{array}{c}V e \\
(\mathrm{~km} / \mathrm{h})\end{array}$} & \multirow{4}{*}{$\begin{array}{c}V_{c} \\
(\mathrm{~km} / \mathrm{h})\end{array}$} & \multirow{4}{*}{$\begin{array}{l}R^{\mathrm{a}} \\
(\mathrm{m})\end{array}$} & \multirow{4}{*}{$\begin{array}{c}d_{c i r} b \\
(\mathrm{~m})\end{array}$} & \multicolumn{5}{|c|}{ Required Sight Distance $D_{1}(\mathrm{~m})$} \\
\hline & & & & \multirow{3}{*}{$\begin{array}{l}\text { Linear } \\
r=1\end{array}$} & \multicolumn{4}{|c|}{ Nonlinear } \\
\hline & & & & & \multicolumn{2}{|c|}{$r=0.5$} & \multicolumn{2}{|c|}{$r=1.5$} \\
\hline & & & & & Value & Diff $(\%)^{c}$ & Value & Diff (\%) \\
\hline \multirow[t]{2}{*}{30} & 30 & 24 & 12.4 & 45.1 & 45.1 & 0.0 & 45.1 & 0.0 \\
\hline & 20 & 9 & 4.2 & 39.8 & 42.2 & 6.0 & 38.8 & -2.5 \\
\hline \multirow[t]{3}{*}{40} & 40 & 50 & 26.7 & 60.2 & 60.2 & 0.0 & 60.2 & 0.0 \\
\hline & 30 & 24 & 12.4 & 52.8 & 55.4 & 4.9 & 51.8 & -1.9 \\
\hline & 20 & 9 & 4.2 & 43 & 51.3 & 19.3 & 39.5 & -8.1 \\
\hline \multirow[t]{3}{*}{50} & 50 & 94 & 48.3 & 75.2 & 75.2 & 0.0 & 75.2 & 0.0 \\
\hline & 40 & 50 & 26.7 & 65.3 & 68 & 4.1 & 64.3 & -1.5 \\
\hline & 30 & 24 & 12.4 & 54.3 & 60.9 & 12.2 & 51.6 & -5.0 \\
\hline \multirow[t]{3}{*}{60} & 60 & 149 & 78.5 & 90.2 & 90.2 & 0.0 & 90.2 & 0.0 \\
\hline & 50 & 94 & 48.3 & 77.4 & 79.4 & 2.6 & 76.7 & -0.9 \\
\hline & 40 & 50 & 26.7 & 65.6 & 69.9 & 6.6 & 63.9 & -2.6 \\
\hline \multirow[t]{3}{*}{70} & 60 & 149 & 78.5 & 90.5 & 90.8 & 0.3 & 90.4 & -0.1 \\
\hline & 50 & 94 & 48.3 & 77.4 & 79.4 & 2.6 & 76.7 & -0.9 \\
\hline & 40 & 50 & 26.7 & 65.6 & 69.9 & 6.6 & 63.9 & -2.6 \\
\hline
\end{tabular}
difference equals zero.

Table 2. Effect of the deceleration shape parameter on the sight distance $D_{1}$ (deterministic).

a Minimum radius for $V_{c}$ based on the American Association of State Highway and Transportation Officials (AASHTO) lateral friction coefficients for urban low speeds and $e=0.02 ;{ }^{b}$ Length of entry vehicle path on a circulatory roadway based on Equation (11) (assuming $\theta=30$ degrees); ${ }^{c}$ Difference between the values for the linear and nonlinear deceleration profiles. 


\section{Proposed Reliability Method}

\subsection{FOSM Reliability Method}

The FOSM method is simpler and more straightforward than other advanced methods. In this method, a performance function is expanded at the mean values of the random variables. Let the safety margin, $S M$, be a nonlinear performance function that involves several random variables, $x_{i}, i=1,2, \ldots, n$. Then,

$$
S M=f\left(x_{1}, x, \ldots, x_{n}\right) .
$$

The FOSM method uses a Taylor series expansion about the mean values of the random variables, and expresses the mean and variance of the random variable $S M, E[S M]$, and var[SM], respectively, as follows:

$$
\begin{gathered}
E[S M] \cong f\left(\mu_{x 1}, \mu_{x 2}, \ldots, \mu_{x n}\right), \\
\operatorname{var}[S M] \cong \sum_{i=1}^{n}\left(\frac{\partial f}{\partial x_{i}}\right)^{2} \sigma_{x i}^{2}+\sum_{i \neq}^{n} \sum_{j}^{n}\left(\frac{\partial f}{\partial x_{i}}\right)\left(\frac{\partial f}{\partial x_{j}}\right) \operatorname{cov}\left[x_{i}, x_{j}\right], \\
\operatorname{cov}\left[x_{i}, x_{j}\right]=\rho_{x i, x j} \sigma_{x i} \sigma_{x j},
\end{gathered}
$$

where $\mu_{x i}=$ the mean of the random variable $x_{i}, \sigma_{x i}{ }^{2}=$ the variance of the random variable $x_{i}, \sigma_{x i}=$ the standard deviation of the random variable $x_{i}$, and $\rho_{x i}, x j=$ Pearson's coefficient of the correlation between $x_{i}$ and $x_{j}$. Furthermore, the coefficient of variation of the random variable $x_{i}, C V_{x i}$, which is a dimensionless measure of dispersion, is given by:

$$
C V_{x i}=\frac{\sigma_{x i}}{\mu_{x i}}
$$

The reliability index, $\beta$, defines the number of standard deviations between the expected value of $S M$ and the limit state, $S M=0$. That is,

$$
\beta=\frac{E[S M]}{\sqrt{\operatorname{var}[S M]}} .
$$

Assuming that $S M$ is normally distributed, $P_{n c}$ can be estimated as:

$$
P_{n c}=\phi(-\beta)=1-\phi(\beta),
$$

where $\Phi(-\beta)=$ the area under the standard normal variate PDF (probability distribution function) from $-\infty$ to $-\beta$, obtained using standard normal variate tables. For example, for $\beta=1.64, P_{n c}=5 \%$. The larger $\beta$ is, the smaller the $P_{n c}$. If $S M$ is linear, the mean and standard deviation will be accurately assessed using the FOSM method. However, if SM is nonlinear, the FOSM analysis may introduce errors. For more details about reliability analysis, the reader is referred to Benjamin and Cornell [32], Smith [33], and Haukaas [34].

\subsection{Reliability Analysis of ISD}

\subsubsection{Distance $\mathrm{D}_{1}$}

The safety margin is defined as the difference between the supplied and demanded length of the sight distance leg to the entry vehicle. That is,

$$
S M_{1}=D_{1 \text { supply }}-D_{1}
$$


where $D_{1 \text { supply }}$ denotes the length of $D_{1}$ supplied (m) and $D_{1}=$ the length of $D_{1}$ demanded $(\mathrm{m})$, which equals $D_{1}$ from Equations (13), (16), and (17) for Cases 1-3, respectively. In general, the expected value and variance of the $S M_{1}, E\left[S M_{1}\right]$, and $\operatorname{var}\left[S M_{1}\right]$, based on Equations (22) and (23), are given by:

$$
\begin{gathered}
E\left[S M_{1}\right]=D_{1 \text { supply }}-E\left[D_{1}\right], \\
\operatorname{var}\left[S M_{1}\right]=\left(\frac{\partial S M_{1}}{\partial v_{s}}\right)^{2} \sigma_{v_{s}}^{2}+\left(\frac{\partial S M_{1}}{\partial v_{c}}\right)^{2} \sigma_{v_{c}}^{2}+\left(\frac{\partial S M_{1}}{\partial \alpha}\right)^{2} \sigma_{\alpha}^{2}+\left(\frac{\partial S M_{1}}{\partial t_{c}}\right)^{2} \sigma_{t_{c}}^{2}+\left(\frac{\partial S M_{1}}{\partial r}\right)^{2} \sigma_{r}^{2}+ \\
2\left(\frac{\partial S M_{1}}{\partial v_{s}}\right)\left(\frac{\partial S M_{1}}{\partial \alpha}\right) \operatorname{cov}\left[v_{s}, \alpha\right]+2\left(\frac{\partial S M_{1}}{\partial v_{s}}\right)\left(\frac{\partial S M_{1}}{\partial t_{c}}\right) \operatorname{cov}\left[v_{s}, t_{c}\right]+ \\
2\left(\frac{\partial S M_{1}}{\partial v_{s}}\right)\left(\frac{\partial S M_{1}}{\partial r}\right) \operatorname{cov}\left[v_{s}, r\right]+2\left(\frac{\partial S M_{1}}{\partial v_{c}}\right)\left(\frac{\partial S M_{1}}{\partial \alpha}\right) \operatorname{cov}\left[v_{c}, \alpha\right],
\end{gathered}
$$

where $E\left[D_{1}\right]$ = the expected value of the demanded sight distance $D_{1}$, which is obtained by substituting the mean values of the component random variables into the $D_{1}$ equation of the respective case. Note that Equation (29) includes the correlations between several variables: $\left(v_{e}, t_{c}\right),\left(v_{e}, a\right),\left(v_{e}, r\right)$, and $\left(v_{c}, a\right)$. The first three correlations are positive, while the fourth is negative. The first derivatives are given next for the three cases.

\section{Case 1:}

Substituting $D_{1}$ from Equation (13) into Equation (27), the first derivatives of $S M_{1}$, with respect to $v_{c}$ and $t_{c}$, can be derived as:

$$
\begin{gathered}
\frac{\partial S M_{1}}{\partial v_{c}}=-\mu_{t c}, \\
\frac{\partial S M_{1}}{\partial t_{c}}=-\mu_{v c},
\end{gathered}
$$

where $\mu$ denotes the mean of the indicated random variable.

Case 2:

Substituting $t^{\prime}$ and $v_{e}{ }^{\prime}$ from Equations (14) and (15) and $d_{c i r}$ and $t_{c i r}$ from Equations (11) and (12) into Equation (16), then substituting $D_{1}$ into Equation (27), the first derivatives of $S M_{1}$ with respect to $v_{c}, a, t_{c}$, and $r$ can be derived as

$$
\begin{gathered}
\frac{\partial S M_{1}}{\partial v_{c}} \mu_{t c} \\
=-\frac{\mu_{t c}}{2}-1.3305 \mu_{t_{c i r}} \\
-\frac{\left(\mu_{t c}-\mu_{t_{c i r}}\right)\left[\mu_{v c} \mu_{r}+\mu_{a}\left(\mu_{t c}-\mu_{c i r}\right)\right]-0.0729 \mu_{u_{c}}^{0.661}\left[2 \mu_{a}^{2}\left(\mu_{t c}-\mu_{c i r}\right)^{2}+3 \mu_{a} \mu_{v c}\left(\mu_{t c}-\mu_{t_{c i r}}\right)+\mu_{v c c}^{2} \mu_{r}\right]}{2 M} \\
\frac{\partial S M_{1}}{\partial a}=-\frac{\mu_{a}\left(\mu_{t c}-\mu_{t_{c i r}}\right)^{3}+\mu_{v c}\left(\mu_{t c}-\mu_{t_{c i r}}\right)^{2}}{2 M} \\
\frac{\partial S M_{1}}{\partial t_{c}}=-\frac{\mu_{v c}}{2}-\frac{\mu_{v c}^{2} \mu_{r}+2 \mu_{a}^{2}\left(\mu_{t c}-\mu_{c i r}\right)^{2}+3 \mu_{a} \mu_{v c}\left(\mu_{t c}-\mu_{t_{c i r}}\right)}{2 M} \\
\frac{\partial S M_{1}}{\partial r}=\frac{\mu_{a}\left(\mu_{t c}-\mu_{t_{c i r}}\right)^{2}\left[\mu_{a}\left(\mu_{t c}-\mu_{t_{c i r}}\right)+2 \mu_{v c}\right]}{4 \mu_{r} M}
\end{gathered}
$$

where $M=\sqrt{\mu_{r}^{2} \mu_{v c}^{2}+\mu_{r}\left[\mu_{a}^{2}\left(\mu_{t c}-\mu_{t_{c i r}}\right)^{2}+2 \mu_{a} \mu_{v c}\left(\mu_{t c}-\mu_{t_{c i r}}\right)\right]}$.

Case 3:

Substituting $t$ and $d_{c i r}$ from Equations (5) and (11) into Equation (17), then substituting $D_{1}$ into Equation (27), the first derivatives of $S M_{1}$ with respect to $v_{e}, v_{c}, a, t_{c}$, and $r$ can be derived as

$$
\frac{\partial S M_{1}}{\partial v_{e}}=\frac{4 \mu_{v e}-3 \mu_{v c}}{2 \mu_{a}}-\frac{\left(\mu_{r}-1\right) \mu_{v c}^{2}+\left(2 \mu_{v e}-\mu_{v c}\right) \mu_{v e}}{2 \mu_{a} K}-\mu_{t c}+\mu_{t_{c i r}}
$$




$$
\begin{gathered}
\frac{\partial S M_{1}}{\partial v_{c}}=\frac{2 \mu_{v c}-3 \mu_{v e}}{2 \mu_{a}}-\frac{\left(\mu_{r}-1\right)\left(\mu_{v e}-2 \mu_{v c}\right) \mu_{v c}-\mu_{v e}^{2}}{2 \mu_{a} K}-2.661 \mu_{t_{c i r}} \cdot\left(1-\frac{\mu_{v e}}{\mu_{v c}}\right)-0.0439 \mu_{v e} \mu_{v_{c}}^{0.661}, \\
\frac{\partial S M_{1}}{\partial a}=\frac{\left(\mu_{v c}-\mu_{v e}\right)\left[2 \mu_{r} \mu_{v e}-\mu_{r} \mu_{v c}-K\right]}{2 \mu_{a}^{2} \mu_{r}}, \\
\frac{\partial S M_{1}}{\partial t_{c}}=-\mu_{v e}, \\
\frac{\partial S M_{1}}{\partial r}=\frac{\mu_{t}\left(\mu_{v e}^{2}-\mu_{v c}^{2}\right)}{4 \mu_{r} K},
\end{gathered}
$$

where $K=\sqrt{\mu_{r}^{2} \mu_{v c}^{2}+\mu_{r}\left(\mu_{v e}^{2}-\mu_{v c}^{2}\right)}$. Based on Equations (25) and (28), then:

$$
D_{1 \text { supply }}=\sqrt{\operatorname{var}\left[S M_{1}\right]} \beta+\mathrm{E}\left[D_{1}\right] .
$$

Then, $D_{1 \text { supply }}$ is calculated for various values of $P_{n c}$. Note that the conditions for the three cases presented previously involves random variables, and therefore these conditions also involve uncertainty. The probabilistic equivalent of the deterministic conditions for the three cases are presented in Appendix A.

\subsubsection{Distance $\mathrm{D}_{2}$}

The safety margin, defined as the difference between the supplied and demanded lengths of the sight distance leg to the circulating vehicle, is given by:

$$
S M_{2}=D_{2 \text { supply }}-D_{2}
$$

where $D_{2 \text { supply }}$ denotes the length of $D_{2}$ supplied (m) and $D_{2}=$ the length of $D_{2}$ demanded (m), which equals $D_{2}$ from Equation (19). Then,

$$
S M_{2}=D_{2 s u p p l y}-t_{c} v_{c}
$$

where the random variables are $t_{c}$, and $v_{c}$. The expected value and variance of the $S M_{2}, E\left[S M_{2}\right]$, and $\operatorname{var}\left[\mathrm{SM}_{2}\right]$, based on Equations (21) and (22), are given by:

$$
\begin{gathered}
E\left[S M_{2}\right]=D_{2 \text { supply }}-\mu_{t c} \mu_{v c}, \\
\operatorname{var}\left[S M_{2}\right]=\left(\frac{\partial S M_{2}}{\partial t_{c}}\right)^{2} \sigma_{t_{c}}^{2}+\left(\frac{\partial S M_{2}}{\partial v_{c}}\right)^{2} \sigma_{v_{c}}^{2}+2\left(\frac{\partial S M_{2}}{\partial t_{c}}\right)\left(\frac{\partial S M_{2}}{\partial v_{c}}\right) \operatorname{cov}\left[t_{c}, v_{c}\right],
\end{gathered}
$$

where the first derivatives with respect to $v_{c}$ and $t_{c}$ are given by the right sides of Equations (30) and (31), respectively. Based on Equations (25) and (44), then:

$$
D_{2 s u p p l y}=\sqrt{\operatorname{var}\left[S M_{2}\right]} \beta+\mu_{t c} \mu_{v c} .
$$

Then, $D_{2 s u p p l y}$ is calculated for various values of $P_{n c}$.

\subsection{Verification}

The proposed reliability methods for $D_{1}$ and $D_{2}$ were verified using Monte Carlo simulation. The probability distribution of the safety margin of the mathematical method, based on $E\left[S M_{1}\right]$, $\operatorname{var}\left[S M_{1}\right]$, and $E\left[S M_{2}\right], \operatorname{var}\left[S M_{2}\right]$ was compared with that of the simulation. The mean values of the random variables were as follows. For $D_{1}$ (Case 1), $\mu_{v e}=12.85 \mathrm{~m} / \mathrm{s}$ and $\mu_{v c}=10.28 \mathrm{~m} / \mathrm{s}$, and for $D_{1}$ (Case 2), $\mu_{v e}=12.85 \mathrm{~m} / \mathrm{s}$ and $\mu_{v c}=7.71 \mathrm{~m} / \mathrm{s}$. For both cases, $\mu_{t c}=5 \mathrm{~s}, \mu_{a}=1.3 \mathrm{~m} / \mathrm{s}^{2}$, and $\mu_{r}=0.5$. 
The coefficient of variation was $5 \%$ for all variables. The mean entry and circulatory speeds correspond to the design speeds of $50 \mathrm{~km} / \mathrm{h}$ and $40 \mathrm{~km} / \mathrm{h}$, respectively, which were assumed to represent the $95 \%$ percentile speed, as discussed later in data preparation. For $D_{2}, \mu_{v c}=7.71 \mathrm{~m} / \mathrm{s}$ and $\mu_{t c}=5 \mathrm{~s}$ with coefficient of variation $(\mathrm{CV})=5 \%$, where the mean circulatory speed corresponds to a design speed of $30 \mathrm{~km} / \mathrm{h}$. All the random variables were assumed to be normally distributed in the simulation. For simplicity, the variables were assumed to be uncorrelated. Note that the FOSM reliability method requires no assumptions about the distributions of the input random variables.

The simulation involved generating 30,000 random values of the component random variables of the respective equations for $D_{1}\left(v_{e}, v_{c}, t_{c}, a\right.$, and $\left.r\right)$ and $D_{2}\left(v_{c}, t_{c}\right)$. The probability distributions of the component random variables were assumed to be normal, with the means and standard deviations calculated from the data. The generated random values of the component variables were then substituted into the respective equations, resulting in 30,000 values of the dependent random variable. Using these values, their means and standard deviations were calculated along with their histograms. The reliability index was $\beta=1.64\left(P_{n c}=5 \%\right)$. For $D_{1}$ (Case 2$)$, the mean and standard deviation of the safety margin of the mathematical model were $E\left[S M_{1}\right],=6.818 \mathrm{~m}$ and $\sigma_{S \mathrm{SM} 1}=4.157 \mathrm{~m}$, compared with the simulation values of 6.761 and 4.155 (Figure 4a). The results for Case 3 were also very close (Figure $4 \mathrm{~b})$. For $D_{2}$, the mathematical and simulated values were $(4.469,2.725)$ and $(4.512$, 2.718), respectively (Figure 4c). As noted, the means and standard deviations of the simulation and mathematical formulas show excellent agreement. In particular, the close standard deviations of the mathematical and simulation methods verify the rather complex first derivatives of Cases 2 and 3 of $D_{1}$. In addition, the simulation results show that the probability distributions of the design variables are very close to the normal distribution.

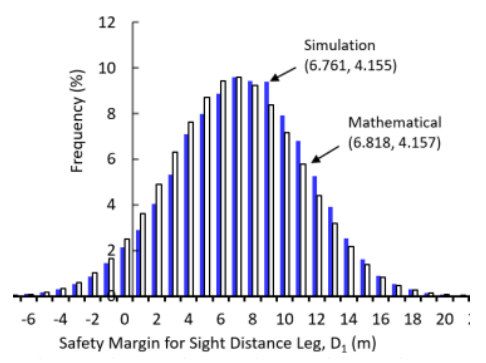

(a) $D_{1}$ (Case 2)

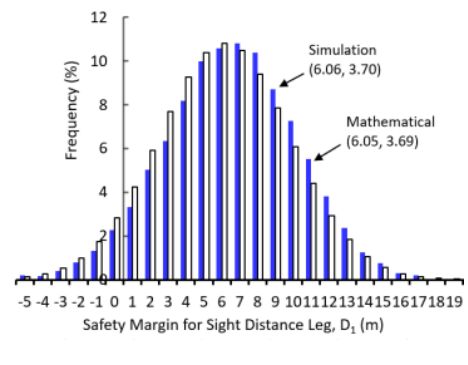

(b) $\mathrm{D}_{1}$ (Case 3)

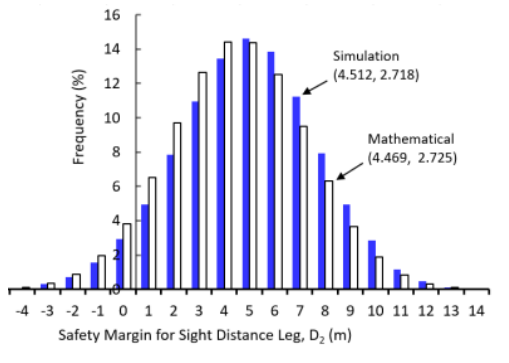

(c) $\mathrm{D}_{2}$

Figure 4. Comparison of the first-order second-moment method (FOSM) results of $D_{1}$ and $D_{2}$ by the analytical method and Monte Carlo simulation: (a) $D_{1}$ (Case 2, $V_{e}=50 \mathrm{~km} / \mathrm{h}, V_{c}=40 \mathrm{~km}$ ), (b) $D_{1}$ (Case $\left.3, V_{e}=50 \mathrm{~km} / \mathrm{h}, V_{c}=30 \mathrm{~km}\right)$, and (c) $D_{2}\left(V_{c}=30 \mathrm{~km}\right)$.

\section{Application}

\subsection{Data Preparation}

Data related to the means and standard deviations of the component random variables are required for the application of reliability methods. Most data were determined from the percentile values of the random variables reported in the literature. For normally distributed random variables, the relationship between the mean and extreme value is given by Hussain and Easa [26] as:

$$
\mu_{X i}=\frac{E_{X i}}{\left(1+z C V_{x i}\right)}
$$

where $\mu_{X i}$ denotes the mean of the random variable $x_{i}, E_{x i}$ denotes the extreme value corresponding to a certain percentile value of the random variable $x_{i}, z$ denotes the number of standard deviations of the normal distribution corresponding to a certain percentile value, and $C V_{X i}$ denotes the coefficient of variation of the random variable. Note that $z$ is positive for variables for which the extreme values are 
based on a high percentile value and negative when low percentile values should be used. For example, the value of $z$ for a random variable with respect to its 95th percentile value is 1.64 and -1.64 for the 5 th percentile.

Table 3 shows the selected values for various random variables that were used for establishing the design aids. The 95th percentile values represented the design speeds of $V_{e}, V_{c}$, and $t_{c}$. On the other hand, the 10th percentile value represented the design value for $a$, since smaller values of the deceleration rate result in larger values of $D_{1}$. For the deceleration shape parameter, there is currently no guidance for the roundabout deceleration profile (without stopping). However, previous research on vehicle stopping [29] showed that the value of $r$ ranged from 0.4 to 1.7, where the approach speed for $r=1$ was $77.2 \mathrm{~km} / \mathrm{h}$ (48 mph). Speeds less than this limiting value corresponded to $r<1$, and speeds larger than this value corresponded to $r>1$. Since the entry speeds for roundabouts are typically less than $70 \mathrm{~km} / \mathrm{h}$, two values were selected for establishing the design aids: $r=0.5$ (nonlinear deceleration) and $r=1$ (linear deceleration).

Table 3. Selected values of various random variables.

\begin{tabular}{cccccc}
\hline Variable & Unit & Extreme Value & Percentile $^{\mathbf{a}}$ & $\mathbf{z}$ & Mean Value $^{\mathbf{b}}$ \\
\hline$V_{e}$ & $\mathrm{~km} / \mathrm{h}$ & 30 to 70 & $95 \%$ & 1.64 & 25.8 to 60.1 \\
$V_{c}$ & $\mathrm{~km} / \mathrm{h}$ & 20 to 60 & $95 \%$ & 1.64 & 17.2 to 51.5 \\
$t_{c}$ & $\mathrm{~s}$ & 5.8 & $95 \%$ & 1.64 & 5 \\
$a$ & $\mathrm{~m} / \mathrm{s}^{2}$ & 1.2 & $10 \%$ & -1.28 & 1.3 \\
\hline
\end{tabular}

a Percentile values are based on the literature or are assumed; ${ }^{\mathrm{b}}$ The mean values are calculated assuming $C V=10 \%$ for all variables.

\subsection{Design Values of ISD}

Design values of $D_{1}$ and $D_{2}$ were established using the reliability-based method of Equations (41) and (46), respectively, for $C V=5 \%$ and $10 \%$ and $P_{n c}=1 \%, 5 \%$, and $10 \%$. For $D_{1}$, the values were established for different combinations of $V_{e}$ and $V_{c}$ and for linear $(r=0.5)$ and nonlinear $(\mathrm{r}=1.0)$ deceleration profiles, as shown in Table 4 . As noted, larger design values are required for a larger $C V$ and smaller $P_{n c}$. The deterministic values are also shown in the table. A comparison of the deterministic and reliability-based values for $V_{e}=60 \mathrm{~km} / \mathrm{h}$ of Table 4 are shown graphically in Figure 5. As noted, the deterministic values correspond to a low probability of non-compliance (about $P_{n c}=1 \%$ ), indicating that such values are conservative. This finding is consistent with that of Easa [23], where the deterministic values for uncontrolled intersections corresponded to a very small probability of non-compliance. This is not surprising, since the deterministic method uses very high or very low percentile values (depending on the nature of the random variable). Note also that the trends of the design values for the linear and nonlinear deceleration profiles are similar, except that the values for the nonlinear profile $(r=0.5)$ are greater, as previously discussed.

The design values for $D_{2}$ are shown in Table 5 for $V_{c}$ ranging from 20 to $60 \mathrm{~km} / \mathrm{h}$. As noted, similarly to $D_{1}$, the deterministic values also lie close to the reliability-based values for $P_{n c}=1 \%$. Note that the design values of $D_{1}$ and $D_{2}$ do not depend on any specific geometric configuration of the roundabout, and therefore they are applicable to all types of roundabouts. Only $D_{1}$ depends on the minimum radius of a circulatory roadway. 
Table 4. Reliability-based design values of the required sight distance for entry vehicle $D_{1}$ for linear and nonlinear deceleration profiles.

\begin{tabular}{|c|c|c|c|c|c|c|c|c|}
\hline \multirow{3}{*}{$\begin{array}{c}V_{e} \\
(\mathrm{~km} / \mathrm{h})\end{array}$} & \multirow{3}{*}{$\begin{array}{c}V_{c} \\
(\mathrm{~km} / \mathrm{h})\end{array}$} & \multirow{3}{*}{$\begin{array}{c}\text { Deterministic } D_{1} \\
\text { (m) }\end{array}$} & \multicolumn{6}{|c|}{ Reliability-Based $D_{1}(\mathrm{~m})$} \\
\hline & & & \multicolumn{3}{|c|}{$\mathrm{CV}=5 \%$} & \multicolumn{3}{|c|}{$\mathrm{CV}=10 \%$} \\
\hline & & & $P_{n c}=1 \%$ & $P_{n c}=5 \%$ & $P_{n c}=10 \%$ & $P_{n c}=1 \%$ & $P_{n c}=5 \%$ & $P_{n c}=10 \%$ \\
\hline \multicolumn{9}{|c|}{ (a) Deceleration Shape Parameter, $r=0.5$} \\
\hline \multirow[t]{2}{*}{30} & 30 & 46 & 46 & 44 & 43 & 49 & 46 & 43 \\
\hline & 20 & 43 & 43 & 41 & 40 & 47 & 43 & 41 \\
\hline \multirow[t]{3}{*}{40} & 40 & 61 & 61 & 58 & 57 & 80 & 74 & 71 \\
\hline & 30 & 56 & 57 & 54 & 53 & 72 & 66 & 63 \\
\hline & 20 & 52 & 55 & 52 & 51 & 63 & 57 & 55 \\
\hline \multirow[t]{3}{*}{50} & 50 & 76 & 75 & 72 & 70 & 89 & 82 & 79 \\
\hline & 40 & 69 & 72 & 69 & 67 & 80 & 74 & 71 \\
\hline & 30 & 61 & 64 & 61 & 60 & 72 & 66 & 63 \\
\hline \multirow[t]{3}{*}{60} & 60 & 91 & 91 & 87 & 85 & 98 & 90 & 88 \\
\hline & 50 & 80 & 81 & 77 & 76 & 89 & 82 & 79 \\
\hline & 40 & 70 & 72 & 69 & 67 & 80 & 74 & 71 \\
\hline \multirow[t]{3}{*}{70} & 60 & 91 & 91 & 87 & 85 & 98 & 91 & 88 \\
\hline & 50 & 80 & 81 & 77 & 76 & 89 & 82 & 79 \\
\hline & 40 & 70 & 72 & 69 & 67 & 80 & 74 & 71 \\
\hline \multicolumn{9}{|c|}{ (b) Deceleration shape parameter, $r=1$. } \\
\hline \multirow[t]{2}{*}{30} & 30 & 46 & 46 & 44 & 43 & 49 & 46 & 43 \\
\hline & 20 & 40 & 41 & 39 & 38 & 44 & 41 & 39 \\
\hline \multirow[t]{3}{*}{40} & 40 & 61 & 61 & 58 & 57 & 80 & 68 & 65 \\
\hline & 30 & 53 & 54 & 51 & 50 & 62 & 57 & 55 \\
\hline & 20 & 44 & 46 & 43 & 42 & 51 & 47 & 45 \\
\hline \multirow[t]{3}{*}{50} & 50 & 76 & 75 & 72 & 70 & 89 & 78 & 75 \\
\hline & 40 & 66 & 67 & 64 & 63 & 73 & 68 & 65 \\
\hline & 30 & 55 & 56 & 54 & 53 & 62 & 57 & 55 \\
\hline \multirow[t]{3}{*}{60} & 60 & 91 & 91 & 87 & 85 & 98 & 90 & 86 \\
\hline & 50 & 78 & 78 & 75 & 73 & 84 & 78 & 75 \\
\hline & 40 & 66 & 67 & 64 & 63 & 73 & 68 & 65 \\
\hline \multirow[t]{3}{*}{70} & 60 & 91 & 91 & 87 & 85 & 97 & 90 & 86 \\
\hline & 50 & 78 & 78 & 75 & 73 & 84 & 78 & 75 \\
\hline & 40 & 66 & 67 & 64 & 63 & 73 & 68 & 65 \\
\hline
\end{tabular}

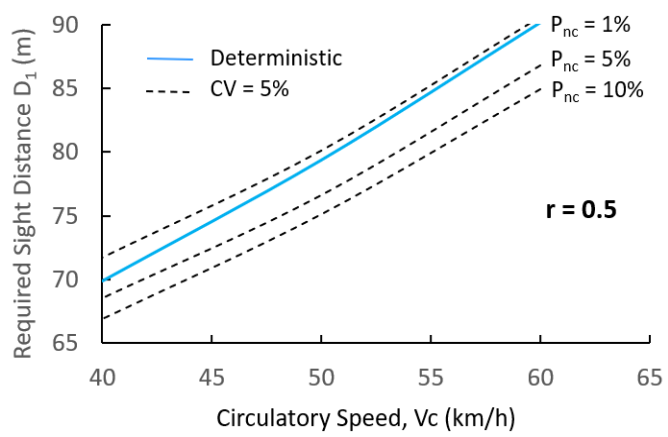

(a) Nonlinear deceleration rate $(r=0.5)$.

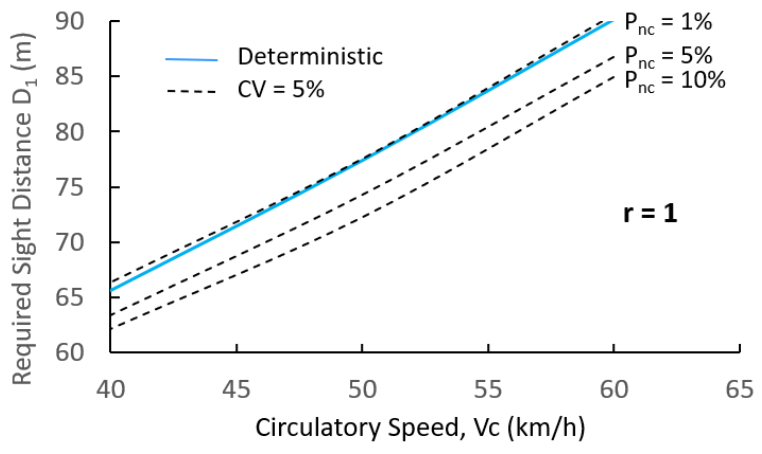

(b) Linear deceleration rate $(r=1)$.

Figure 5. Comparison of the deterministic and reliability-based values of required sight distance $D_{1}$ for linear and nonlinear deceleration profiles $\left(V_{e}=60 \mathrm{~km} / \mathrm{h}\right)$. (a) Nonlinear deceleration rate $(r=0.5)$.

(b) Linear deceleration rate $(r=1)$. 
Table 5. Reliability-based design values of the required sight distance for circulating vehicle $D_{2}$.

\begin{tabular}{|c|c|c|c|c|c|c|c|}
\hline \multirow{3}{*}{$\begin{array}{c}V_{c} \\
(\mathrm{~km} / \mathrm{h})\end{array}$} & \multirow{3}{*}{$\begin{array}{l}\text { Deterministic } \\
\text { (m) }\end{array}$} & \multicolumn{6}{|c|}{ Reliability-Based $D_{2}(\mathrm{~m})$} \\
\hline & & \multicolumn{3}{|c|}{$\mathrm{CV}=5 \%$} & \multicolumn{3}{|c|}{$C V=10 \%$} \\
\hline & & $P_{n c}=1 \%$ & $P_{n c}=5 \%$ & $P_{n c}=10 \%$ & $P_{n c}=1 \%$ & $P_{n c}=5 \%$ & $P_{n c}=10 \%$ \\
\hline 20 & 33 & 31 & 30 & 29 & 34 & 31 & 30 \\
\hline 25 & 41 & 39 & 37 & 36 & 42 & 39 & 37 \\
\hline 30 & 49 & 47 & 45 & 43 & 51 & 46 & 44 \\
\hline 35 & 57 & 54 & 52 & 50 & 59 & 54 & 51 \\
\hline 40 & 65 & 62 & 59 & 58 & 68 & 62 & 59 \\
\hline 45 & 73 & 70 & 66 & 65 & 76 & 69 & 66 \\
\hline 50 & 81 & 78 & 74 & 72 & 84 & 77 & 73 \\
\hline 55 & 89 & 85 & 81 & 79 & 93 & 84 & 80 \\
\hline 60 & 98 & 93 & 88 & 86 & 101 & 92 & 88 \\
\hline
\end{tabular}

\subsection{Lateral Clearance Needs: Special Case}

Although the design values of ISD are applicable to any type of roundabout, the lateral clearance needs would vary from one roundabout to another depending on its specific geometry. Only in the special case of single-lane symmetrical roundabouts can lateral clearance needs be mathematically formulated [35]. Note that the lateral clearance formulation in that paper is general and is applicable to any values of ISD (deterministic or reliability-based). For a single-lane symmetrical roundabout, the relation between the entry radius and the radius of the inscribed circle can be derived as:

$$
R_{1}=\frac{\left(R_{c}+w_{c}\right) \cos (\alpha)-w_{1}}{(1-\cos (\alpha))}
$$

where $R_{1}=$ the entry radius $(\mathrm{m}), R_{c}=$ the circulatory roadway radius $(\mathrm{m}), w_{c}=$ the circulatory roadway width, $\alpha=$ the angle between the $y$-axis and the line connecting the centers of the entry and inscribed circle curves $\left(45^{\circ}\right)$, and $w_{1}=$ the distance from the curb to the centerline of the road $(\mathrm{m})$. The inscribed circle radius $R_{n}=R_{c}+w_{c}$. Given $R_{c}$ and $w_{1}, R_{1}$ is calculated using Equation (48).

The geometry of the lateral clearance for a single-lane symmetrical roundabout is shown in Figure 6 for an approach vehicle at the yield line and at $15 \mathrm{~m}$ from the yield line. Given the design values presented in the previous section for the two cases, the corresponding lateral clearance for each case was determined. As noted in Figure $6 \mathrm{a}$ (vehicle at $15 \mathrm{~m}$ from the yield line), the lateral clearance for the sight line $a b^{\prime}$ to the entry vehicle on the left, $C_{d}$, is determined at the tangential point $d$. For the conflicting circulating vehicle, the maximum lateral clearance for the sight line $a b$ is determined. For the conflicting-entering vehicle, after the formulation of the general lateral clearance $C_{f}$, the maximum lateral clearance is determined using optimization as follows:

$$
\text { Maximize } \mathrm{Z}=\mathrm{C}_{f} \text {. }
$$

This is subject to:

$$
d_{L}<d_{f}<d_{U}
$$

where $d_{f}$ denotes the distance of Point $f$ on the central island curb (decision variable), measured from the road centerline (Point $u$ ), and $d_{L}$ and $d_{U}$ denote the arbitrary lower and upper limits of the decision variable, respectively, that cover the possible range of lateral clearance and can be set up in different ways.

In this study, they were set equal to 0 and the distance on the curb from Point $u$ to Point $b$, respectively. Note that the lateral clearance for the central island implies a clear zone where the height of the landscaping and other objects around the outer edge of the central island will be restricted. The driver's eye and object heights should both be $1.08 \mathrm{~m}$. The lateral clearance for a vehicle at the yield line (Figure 6 b) is determined similarly. The detailed formulation of lateral clearance can be 
found in Easa [35]. Based on Equations (49) and (50), the lateral clearance needs to the entry vehicle (based on $D_{1}$ of Table 4) and to the circulating vehicle (based on $D_{2}$ of Table 5) are presented in Tables 6 and 7. For $D_{1}$, the values of Table 6 correspond to the lateral clearance, $C_{d}$, at the tangent point $d$ for the sight line $a b^{\prime}$ (Figure 6a). For $D_{2}$, the values of Table 7 correspond to the maximum lateral clearance on the central island for the sight line $e b$ (Figure $6 \mathrm{~b}$ ).

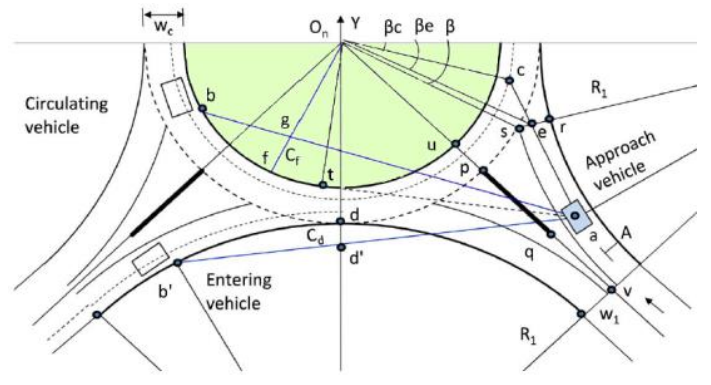

(a) Approach vehicle at $15 \mathrm{~m}$ from the yield line.

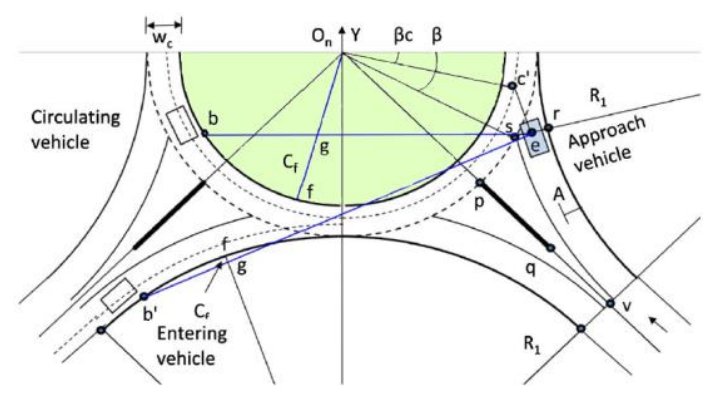

(b) Approach vehicle at the yield line.

Figure 6. Geometry of the lateral clearance of Cases 1 and 2 of ISD [35]. (a) Approach vehicle at $15 \mathrm{~m}$ from the yield line. (b) Approach vehicle at the yield line.

Table 6. Reliability-based maximum lateral clearance needs for the circulating vehicle for single-lane symmetrical roundabouts (approach vehicle at yield line) ${ }^{b}$.

\begin{tabular}{|c|c|c|c|c|c|c|}
\hline \multirow{3}{*}{$\begin{array}{c}V_{c} \\
(\mathrm{~km} / \mathrm{h})\end{array}$} & \multirow{3}{*}{$\begin{array}{c}R c_{\min } \\
(\mathrm{m})\end{array}$} & \multicolumn{5}{|c|}{ Maximum Lateral Clearance, $C_{m}(m)$} \\
\hline & & \multirow{2}{*}{ Deterministic $^{a}$} & \multicolumn{2}{|c|}{$\mathrm{CV}=5 \%$} & \multicolumn{2}{|c|}{$C V=10 \%$} \\
\hline & & & $P_{n c}=5 \%$ & $P_{n c}=10 \%$ & $P_{n c}=5 \%$ & $P_{n c}=10 \%$ \\
\hline 20 & 8.1 & 7.1 & 5.9 & 5.4 & 6.4 & 5.9 \\
\hline 25 & 14.6 & 6.5 & 4.8 & 4.4 & 5.6 & 4.8 \\
\hline 30 & 23.8 & 5.3 & 4.0 & 3.3 & 4.3 & 3.6 \\
\hline 35 & 35.9 & 4.3 & 3.0 & 2.5 & 3.5 & 2.7 \\
\hline 40 & 51.2 & 3.5 & 2.2 & 2.1 & 2.8 & 2.2 \\
\hline 45 & 70.0 & 2.8 & 1.7 & 1.5 & 2.2 & 1.7 \\
\hline 50 & 92.7 & 2.0 & 0.8 & 0.5 & 1.3 & 0.7 \\
\hline
\end{tabular}

a Based on the design speed $V_{c}$ and the 95 th percentile of the critical headway $\mathrm{t}_{\mathrm{c}}{ }^{\mathrm{b}}$ Other roundabout dimensions are $w_{1}=6 \mathrm{~m}$ and $w_{c}=5 \mathrm{~m}$.

Table 7. Reliability-based maximum lateral clearance needs for the entry vehicle for single-lane symmetrical roundabouts, $\mathrm{CV}=10 \%$ (approach vehicle $15 \mathrm{~m}$ from the yield line) ${ }^{\mathrm{a}}$.

\begin{tabular}{|c|c|c|c|c|c|c|c|c|c|c|c|c|}
\hline \multirow{4}{*}{$\begin{array}{c}\text { Entry } \\
\text { Radius } \\
R_{1} \\
(\mathrm{~m})\end{array}$} & \multicolumn{12}{|c|}{ Lateral Clearance, $C_{d}(\mathrm{~m})$} \\
\hline & \multicolumn{4}{|c|}{$V e=30 \mathrm{~km} / \mathrm{h}$} & \multicolumn{4}{|c|}{$V c=40 \mathrm{~km} / \mathrm{h}$} & \multicolumn{4}{|c|}{$V c=50 \mathrm{~km} / \mathrm{h}$} \\
\hline & \multicolumn{2}{|c|}{$V c=20 \mathrm{~km} / \mathrm{h}$} & \multicolumn{2}{|c|}{$V c=30 \mathrm{~km} / \mathrm{h}$} & \multicolumn{2}{|c|}{$V c=20 \mathrm{~km} / \mathrm{h}$} & \multicolumn{2}{|c|}{$V c=30 \mathrm{~km} / \mathrm{h}$} & \multicolumn{2}{|c|}{$V c=30 \mathrm{~km} / \mathrm{h}$} & \multicolumn{2}{|c|}{$V c=40 \mathrm{~km} / \mathrm{h}$} \\
\hline & $\begin{array}{c}P_{n c}= \\
5 \%\end{array}$ & $\begin{array}{c}P_{n c}= \\
10 \%\end{array}$ & $\begin{array}{c}P_{n c}= \\
5 \%\end{array}$ & $\begin{array}{c}P_{n c}= \\
10 \%\end{array}$ & $\begin{array}{c}P_{n c}= \\
5 \%\end{array}$ & $\begin{array}{c}P_{n c}= \\
10 \%\end{array}$ & $\begin{array}{c}P_{n c}= \\
5 \%\end{array}$ & $\begin{array}{c}P_{n c}= \\
10 \%\end{array}$ & $\begin{array}{c}P_{n c}= \\
5 \%\end{array}$ & $\begin{array}{c}P_{n c}= \\
10 \%\end{array}$ & $\begin{array}{c}P_{n c}= \\
5 \%\end{array}$ & $\begin{array}{c}P_{n c}= \\
10 \%\end{array}$ \\
\hline \multicolumn{13}{|c|}{ (a) Deceleration Shape Parameter, $r=0.5$} \\
\hline 20 & 8.1 & 8.4 & 9 & 8.4 & 11.7 & 11.3 & 13.4 & 12.9 & 13.4 & 12.9 & 14.6 & 14.2 \\
\hline 30 & 4.3 & 4.6 & 5.3 & 4.6 & 8.7 & 8.1 & 10.8 & 10.2 & 10.8 & 10.1 & 12.4 & 11.8 \\
\hline 40 & 1.6 & 1.8 & 2.3 & 1.8 & 5.1 & 4.5 & 7.7 & 6.7 & 7.7 & 6.8 & 9.7 & 8.9 \\
\hline 50 & 0.3 & 0.4 & 0.6 & 0.4 & 2.4 & 2 & 4.4 & 3.7 & 4.4 & 3.7 & 6.5 & 5.7 \\
\hline \multicolumn{13}{|c|}{ (b) Deceleration Shape Parameter, $r=1.0$} \\
\hline 20 & 7.5 & 6.8 & 9 & 8.1 & 9.3 & 8.7 & 11.7 & 11.2 & 11.7 & 11.2 & 13.7 & 13.2 \\
\hline 30 & 3.6 & 3.0 & 5.2 & 4.3 & 5.6 & 4.9 & 8.7 & 8.1 & 8.6 & 8.1 & 11.2 & 10.6 \\
\hline 40 & 1.2 & 0.9 & 2.2 & 1.6 & 2.5 & 2 & 5.1 & 4.5 & 5 & 4.5 & 8.2 & 7.4 \\
\hline 50 & 0.1 & 0.0 & 0.6 & 0.3 & 0.7 & 0.5 & 2.4 & 2 & 2.4 & 2 & 4.9 & 4.2 \\
\hline
\end{tabular}




\subsection{Sensitivity Analysis}

A sensitivity analysis was conducted to determine how sensitive the required sight distance is to various input variables. For $D_{1}$, the input data for the base case were $V_{e}=50 \mathrm{~km} / \mathrm{h}, V_{c}=30 \mathrm{~km} / \mathrm{h}$, $t_{c}=5 \mathrm{~s}, a=1.3 \mathrm{~m} / \mathrm{s}^{2}$, and $r=1$, where a capital letter $V$ indicates the speed in $\mathrm{km} / \mathrm{h}$. The coefficient of the variation of all variables was $5 \%$, and the correlations were $\rho_{v e, t c}=0.5, \rho_{v e, t c}=0.5, \rho_{v e, a}=0.5$, $\rho_{v e, r}=0.5$, and $\rho_{v c, a}=-0.5$. The probability of non-compliance was $P_{n c}=5 \%$. One variable of the base scenario was changed at a time, while keeping all other variables at their base values. The mean values were increased by $10 \%$, the $C V$ was increased to $10 \%$, and the correlations were changed to 0.8 .

The results of the sensitivity analysis are shown in Table 8 . As noted, the sight distance $D_{1}$ is very sensitive to the mean value of $t_{c}$ and somewhat sensitive to that of $V_{e}$. The value of $D_{1}$ is also very sensitive to the coefficient of variation of both $V_{c}$ and $t_{c}$ and somewhat sensitive to that of $V_{e}$. The sight distance is somewhat sensitive to the values of the correlation coefficients. In addition, the results show that $D_{2}$ is sensitive to the mean values of $V_{c}$ and $t_{c}$ and to the coefficient of variation of $t_{c}$. Clearly, the mean value and variability of $t_{c}$ substantially affect the ISD and should be accurately determined. In addition, the variability of the circulatory speed is an important variable. Other variables including the correlations have little or moderate effects on the calculated sight distance.

Table 8. Sensitivity of $D_{1}$ and $D_{2}$ to various input variables.

\begin{tabular}{cccc}
\hline $\begin{array}{c}\text { Changed } \\
\text { Variable }\end{array}$ & Value & $\begin{array}{c}\boldsymbol{D}_{\mathbf{1}} \text { or } \boldsymbol{D}_{\mathbf{2}}{ }^{\mathbf{a}} \\
\mathbf{( m )}\end{array}$ & $\begin{array}{c}\text { Diff } \\
\mathbf{( \% )}\end{array}$ \\
\hline \multicolumn{4}{c}{ (a) Sensitivity of $D_{1}$} \\
\hline$V_{c}$ & $55 \mathrm{~km} / \mathrm{h}$ & 45.6 & -4.8 \\
$t_{c}$ & $33 \mathrm{~km} / \mathrm{h}$ & 46.7 & -2.5 \\
$a$ & $5.5 \mathrm{~s}$ & 54.9 & 14.6 \\
$r$ & $1.43 \mathrm{~m} / \mathrm{s}^{2}$ & 48.7 & 1.7 \\
$C V_{\mathrm{ve}}$ & 1.1 & 48.4 & 1.0 \\
$C V_{\mathrm{vc}}$ & $10 \%$ & 44.1 & -7.9 \\
$C V_{\mathrm{tc}}$ & $10 \%$ & 55.0 & 14.8 \\
$C V_{\mathrm{a}}$ & $10 \%$ & 53.5 & 11.7 \\
$C V_{\mathrm{r}}$ & $10 \%$ & 47.4 & -1.0 \\
$\rho_{x i, x j}$ & 0.8 & 47.8 & -0.2 \\
& $(\mathrm{~b}) \mathrm{Sensitivity} \mathrm{of} D_{2}$ & -4.6 \\
\hline$V_{c}$ & $33 \mathrm{~km} / \mathrm{h}$ & 50.9 & 9.9 \\
$t_{c}$ & $5.5 \mathrm{~s}$ & 50.9 & 9.9 \\
$C V_{v c}$ & $10 \%$ & 46.8 & 1.1 \\
$C V_{t c}$ & $10 \%$ & 50.4 & 8.9 \\
$\rho_{v c, t c}$ & 0.8 & 47.0 & 1.5 \\
\hline
\end{tabular}

a The input variables for the base scenario are $V_{e}=50 \mathrm{~km} / \mathrm{h}, V_{c}=30 \mathrm{~km} / \mathrm{h}, t_{c}=5 \mathrm{~s}, a=1.3 \mathrm{~m} / \mathrm{s} 2$, and $r=1$. The corresponding values of $D_{1}$ and $D_{2}$ are $47.9 \mathrm{~m}$ and $46.3 \mathrm{~m}$, respectively.

\section{Conclusions}

The paper has presented a general reliability-based method for roundabout intersection sight distance that is applicable to linear and nonlinear deceleration profiles. The required sight distances to the entry vehicle on the left and the vehicle on the circulatory roadway were modeled using the first-order second moment method of reliability analysis. Based on this study, the following comments are offered:

The developed design values of the ISD legs are applicable to any type of roundabout (with a circular central island). However, the developed lateral clearance needs are applicable only to the special case of single-lane symmetrical roundabouts that have a well-defined and simple relationship between the entry and circulatory curves. The lateral clearance needs for other complex roundabouts 
can be established graphically using the developed ISD values. It should also be noted that the proposed reliability-based model is basically relevant for right-hand driving. The model implements an extended formula of the entry vehicle ISD, which explicitly incorporates the deceleration rate. This formula is based on North American practice [1]. However, the concept of the proposed model can be applied to left-hand driving, which normally implements a different formula for the entry vehicle ISD.

Reliability-based design values for the required ISD for different probabilities of non-compliance and different coefficients of variation were established in this paper. These design values are applicable to any geometry of roundabouts, including symmetrical, skewed, or staggered roundabouts. For $D_{1}$, the only requirement is that the central island should be circular, since the design values are based on a distance around circular central island. The values were based on the minimum radius that corresponds to the design speed of the circulatory roadway. However, the design values can perhaps be used with flatter radii of the central island than the minimum values, since they correspond to smaller lateral clearance needs.

The lateral clearance needs for a vehicle at the yield line or $15 \mathrm{~m}$ from the yield line cannot be generally calculated mathematically, since there are many variations in roundabout geometry. Using the design values of ISD presented in this paper can be used to determine the required lateral clearances graphically or using roundabout software. However, for single-lane roundabouts, which have a well-defined geometry, the lateral clearance needs for the entry and circulatory vehicles are presented in this paper. Note that the lateral clearance needs for the circulatory vehicle were established based on an approach vehicle at the yield line, while those for the entry vehicle were established for an approach vehicle at $15 \mathrm{~m}$ from the yield line, since these locations provide the maximum values [35].

The variabilities of the design variables affect the ISD needs, where a larger coefficient of variation requires a larger ISD length. The mean and variance of the critical headway was the variable that impacted the ISD needs the most. In addition, the existing deterministic method, where the design speeds and percentile values of the critical headway and deceleration rate are used, is very conservative and corresponds to very small values of the probability of non-compliance. In terms of design and regulatory innovations, the proposed method provides the designer with flexibility in cases where the lateral clearance is restricted in the field. In this case, different ISD (and in turn lateral clearance) values corresponding to different reliability levels are available to designers. In addition, speed control alternatives can be explored to maintain satisfactory ISD requirements for the approach vehicles.

More advanced reliability methods, such as AFOSM can be applied to analyze sight distance at roundabouts, however, the results of the FOSM method were close to those of the AFOSM based on an analysis not reported in this paper. In addition, previous research by Greto and Easa [15] showed a difference of generally less than $5 \%$ between the two methods. Given the fact that the non-compliance of ISD needs at roundabouts does not pose a catastrophic event, the application of the simple, straightforward FOSM method is justified.

The FOSM reliability method assumes that the safety margin is normally distributed. This assumption is quite reasonable. According to the Central Limit Theorem, when a variable is a function of several random variables, its probability distribution tends to be normal, regardless of the types of the probability distributions of the component random variables [32]. This assumption was verified in this paper using Monte Carlo simulation. In addition, the simulation has also verified the developed mathematical method of ISD reliability analysis.

In setting up the sightline from the approach vehicle to the entry vehicle on the left, the distance $D_{1}$ from the conflict point to the entry vehicle should be calculated. The Australian guide assumes that the entry vehicle travels at the entry speed for the entire leg [5]. Rodegerdts et al. [1] implemented a more realistic assumption by considering that the entry vehicle travels to the conflict point at the average of the $V e$ and $V_{c}$. Both assumptions would result in conservative later clearance needs. This assumption was subsequently revised by Easa [35] by assuming that the entry vehicle travels at the average of the entry and circulatory speeds prior to reaching the circulatory path. In this case, the use of the average 
speed would indirectly account for the deceleration that occurred before reaching the circulatory path. The present paper has further improved the modeling of the entry-vehicle deceleration by explicitly considering the vehicle deceleration profile of the entry vehicle. Note that setting up the sightline based on the proposed method would be conservative for other entry vehicles from the left that stop at the yield line and $15 \mathrm{~m}$ from the yield line.

There is currently no guidance regarding the selection of the deceleration shape parameter $r$ for roundabout entry vehicles that decelerate from the entry to the circulatory speeds. For roundabouts, where the design speeds are relatively small, the shape parameter is expected to be less than 1 . For this case, the results showed that the nonlinear deceleration rate may require up to $20 \%$ greater sight distance for the entry vehicle than that of the linear case. The authors are currently conducting research to establish design values for the deceleration shape parameter. A relation that expresses the deceleration parameter as a function of $V_{e}$ and $V_{c}$ is being established using measurements from drone and video-based trajectory data.

Author Contributions: Conceptualization: S.M.E.; Methodology: S.M.E., S.L., Y.M.; Formal analysis: S.M.E., S.L., S.A.; Investigation: S.M.E., Y.M., S.L.; Visualization, S.M.E., Y.M., Y.Y.; Validation: S.M.E., Y.Y., S.L., S.A.; Writing-original draft preparation: S.M.E., Y.M., S.L.; Writing-review and editing, S.M.E., Y.M., S.L., S.A., Y.Y.; Supervision and funding acquisition: S.M.E. All authors have read and agreed to the published version of the manuscript.

Funding: This research was financially supported by the Natural Sciences and Engineering Research Council of Canada (NSERC), Grant Number RGPIN-2020-04667.

Acknowledgments: The authors are grateful to three anonymous reviewers for their thorough and most helpful comments.

Conflicts of Interest: The authors declare no conflict of interest. The funders had no role in the design of the study; in the collection, analysis, or interpretation of data; in the writing of the manuscript; or in the decision to publish the results.

\section{Abbreviations}

The following notations are used in this paper:

$\begin{array}{ll}a & \text { Deceleration rate of linear profile }\left(\mathrm{m} / \mathrm{s}^{2}\right) \\ a_{1}, a_{2}, a_{3} & \text { Deceleration rates of nonlinear profile }\left(\mathrm{m} / \mathrm{s}^{2}\right) \\ C V & \text { Coefficient of variation of all random variables } \\ C V_{x i} & \text { Coefficient of variation of random variable xi } \\ d & \text { Deceleration distance }(\mathrm{m}) \\ d_{c i r} & \text { Distance along the circulatory part of the path }(\mathrm{m}) \\ d_{f} & \text { Decision variable for determining maximum lateral clearance } \\ d_{L}, d_{U} & \text { Lower and upper limits of the decision variable df } \\ d_{e} & \text { Distance of the sight distance leg on the entry approach (m) } \\ d^{\prime} & \text { Deceleration distance corresponding to Case } 2 \text { (m) } \\ D_{1} & \text { Sight distance leg of the entry vehicle } \\ D_{2} & \text { Sight distance leg of the circulating vehicle } \\ D_{1 s u p p l y} & \text { Length of } \mathrm{D}_{1} \text { supplied } \\ D_{2 s u p p l y} & \text { Length of } \mathrm{D}_{2} \text { supplied } \\ e & \text { Superlevation of circulatory roadway } \\ E\left[D_{1}\right] & \text { Expected value of } \mathrm{D}_{1} \\ E_{x i} & \text { Extreme value corresponding to a certain percentile value of random variable xi } \\ E[S M] & \text { Mean of random variable SM } \\ P_{n c} & \text { Probability of non-compliance } \\ P D F & \text { Probability distribution function } \\ r & \text { Deceleration shape parameter } \\ R & \text { Minimum radius of the entry or circulatory roadway } \\ R_{1} & \text { Entry radius (m) } \\ R_{c} & \text { Circulatory roadway radius (m) }\end{array}$




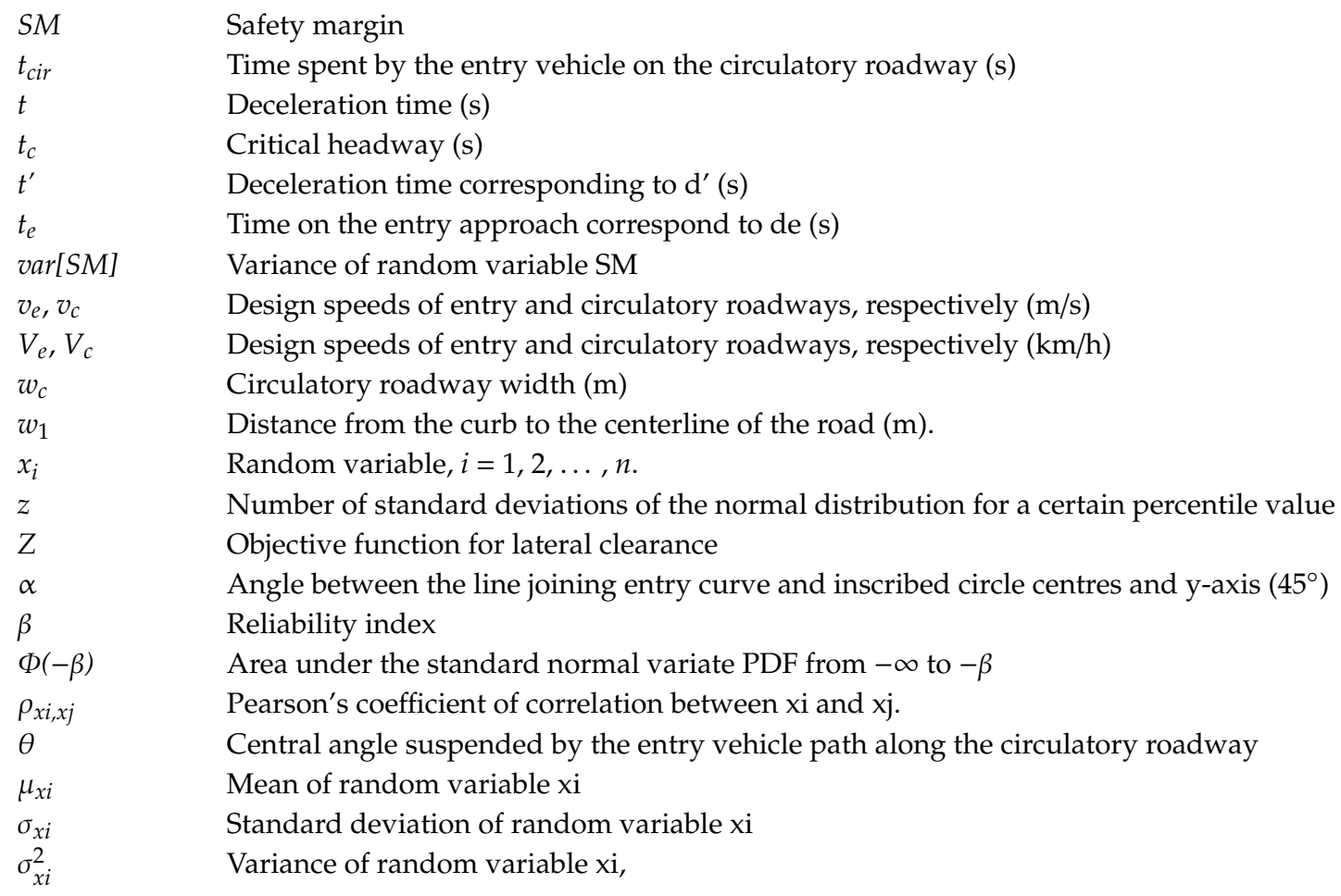

\section{Appendix A Probabilistic Conditions for Cases 1-3 of $D_{\mathbf{1}}$}

Case 1: The deterministic condition of this case is $t_{c} \leq t_{c i r}$ or $t_{c}-t_{c i r} \leq 0$. Therefore, the probabilistic equivalent at the $95 \%$ confidence level is given by:

$$
\left(\mu_{t_{c}}-\mu_{t_{c i r}}\right)+1.64 \sigma_{1} \leq 0
$$

where:

$$
\sigma_{1}=\sqrt{\sigma_{t_{c}}^{2}+\left(0.0729 \mu_{v_{c}}^{0.661}\right)^{2} \sigma_{v_{c}}^{2}}
$$

Case 3: The deterministic condition of this case is $t_{c} \geq t_{c i r}+t$ or:

$$
t_{c}-0.0439 v_{c}^{1.661}-\frac{v_{e}-v_{c}}{a} \geq 0
$$

Therefore, the probabilistic equivalent at the $95 \%$ confidence level is given by:

$$
\left(\mu_{t_{c}}-0.0439 \mu_{v_{c}}^{1.661}-\frac{\mu_{v_{e}}-\mu_{v_{c}}}{\mu_{a}}\right)-\sigma_{2} \geq 0
$$

where:

$$
\begin{gathered}
\sigma_{2}=\sqrt{\sigma_{t_{c}}^{2}+\left(\frac{1}{\mu_{a}}-0.0729 \mu_{v_{c}}^{0.661}\right)^{2} \sigma_{v_{c}}^{2}+\left(-\frac{1}{\mu_{a}}\right)^{2} \sigma_{v_{e}}^{2}+\left(\frac{\mu_{v_{e}}-\mu_{v_{c}}}{\mu_{a}^{2}}\right)^{2} \sigma_{a}^{2}+Q,} \\
Q=2\left(\frac{\mu_{v_{e}}-\mu_{v_{c}}}{\mu_{a}^{2}}\right)\left\{\left(\frac{1}{\mu_{a}}-0.0729 \mu_{v_{c}}^{0.661}\right) \operatorname{cov}\left[a, v_{c}\right]-\left(\frac{1}{\mu_{a}}\right) \operatorname{cov}\left[a, v_{e}\right]\right\}
\end{gathered}
$$

Case 2: Otherwise.

\section{References}

1. Rodegerdts, L.A.; Bansen, J.; Tiesler, C.; Knudsen, J.; Myers, E.; Johnson, M.; Moule, M.; Persaud, B.; Lyon, C.; Hallmark, S.; et al. Roundabouts: An Informational Guide; NCHRP Report 672; Transportation Research Board: Washington, DC, USA, 2010.

2. Transportation Association of Canada. Geometric Design Guide for Canadian Roads; Transportation Association of Canada: Ottawa, ON, Canada, 2017. 
3. American Association of State Highway and Transportation Officials. A Policy on Geometric Design of Highway and Streets; AASHTO: Washington, DC, USA, 2018.

4. Federal Highway Administration (FHWA). Intersection Safety Roundabouts; U.S. Department of Transportation: Washington, DC, USA, 2006.

5. Government of Queensland (GQ). Road planning and design manual. In Roundabouts; Department of Transport and Main Roads: Queensland, Australia, 2013; Chapter 14.

6. Department for Regional Development, Northern Ireland (DRDNI). Geometric Design of Roundabouts; DRDNI: Belfast, UK, 2007; Volume 6.

7. Melchers, R.; Beck, A. Structural Reliability Analysis and Prediction, 3rd ed.; Wiley: New York, NY, USA, 2018.

8. Navin, F. Safety factors for road design: Can they be estimated? Transp. Res. Rec. 1990, 1280, 181-189.

9. Easa, S.M. Reliability-based design of intergreen interval at traffic signals. J. Transp. Eng. 1993, 119, $255-271$. [CrossRef]

10. Easa, S.M. Reliability-based design of sight distance at railroad crossings. Transp. Res. 1994, 28, 1-15. [CrossRef]

11. Easa, S.M. Reliability approach to intersection sight distance design. Transp. Res. Rec. 2000, 1701, 42-52. [CrossRef]

12. Fatema, T.; Hassan, Y. Probabilistic design of freeway entrance speed change lanes considering acceleration and gap acceptance behavior. Transp. Res. Rec. 2013, 2348, 30-37. [CrossRef]

13. Hassan, Y.; Sarhan, M.E.; Salehi, M. Probabilistic model for design of freeway acceleration speed change lanes. Transp. Res. Rec. 2012, 2309, 3-11. [CrossRef]

14. Ibrahim, S.; Sayed, T.; Ismail, K. Methodology for safety optimization of highway cross-sections for horizontal curves with restricted sight distance. Accid. Anal. Prev. 2012, 49, 476-485. [CrossRef]

15. Ismail, S.; Sayed, T. Risk-based framework for accommodating uncertainty in highway geometric design. Can. J. Civ. Eng. 2009, 36, 743-753. [CrossRef]

16. Greto, K.; Easa, S.M. Reliability-based design of truck escape ramps. Can. J. Civ. Eng. 2019, 47, 395-404. [CrossRef]

17. Easa, S.M.; Cheng, J. Reliability analysis of minimum pedestrian green interval for traffic signals. J. Transp. Eng. 2013, 139, 651-659. [CrossRef]

18. Easa, S.M.; Hussain, A. Reliability of sight distance at stop-control intersections. ICE Proc. Transp. 2016, 169, 138-147. [CrossRef]

19. Hussain, A.; Easa, S.M. Reliability analysis of left-turn sight distance at signalized intersections. J. Transp. Eng. 2016, 142, 04015048. [CrossRef]

20. Osama, A.; Sayed, T.; Easa, S.M. Framework for evaluating risk of limited sight distance for permitted left-turn movements: Case study. Can. J. Civ. Eng. 2016, 43, 369-377. [CrossRef]

21. Richl, L.; Sayed, T. Evaluating the safety risk of narrow medians using reliability analysis. J. Transp. Eng. 2006, 132, 5. [CrossRef]

22. De Santos-Berbel, C.; Essa, M.; Sayed, T.; Castro, M. Reliability-based analysis of sight distance modelling for traffic safety. J. Adv. Transp. 2017, 5612849. [CrossRef]

23. Llorca, C.; Moreno, A.T.; Sayed, T.; García, A. Sight distance standards based on observational data risk evaluation of passing. Transp. Res. Rec. 2014, 2404, 18-26. [CrossRef]

24. El-Khoury, J.; Hobeika, J. Incorporating uncertainty into the estimation of the passing sight distance requirements. Comput.-Aided Civ. Infrastruct. Eng. 2007, 22, 347-357. [CrossRef]

25. Sarhan, M.; Hassan, Y. Three-dimensional, probabilistic highway design: Sight distance application. Transp. Res. Rec. 2008, 2060, 10-18. [CrossRef]

26. Wood, J.S.; Donnell, E.T. Stopping sight distance and available sight distance: New model and reliability analysis comparison. Transp. Res. Rec. 2017, 2638, 1-9. [CrossRef]

27. Andrade-Cataño, F.; de Santos-Berbel, C.; Castro, M. Reliability-based safety evaluation of headlight sight distance applied to road sag curve standards. IEEE Access 2020, 8, 43606-43617. [CrossRef]

28. Faizi, J.; Easa, S.M. Reliability of stopping sight distance design at roundabouts. In Annual CSCE Conference; Canadian Society for Civil Engineering: Fredericton, NB, Canada, 2018; pp. 13-16.

29. Wortman, R.H.; Fox, T.C. An evaluation of vehicle deceleration profiles. J. Adv. Transp. 1994, 28, $203-215$. [CrossRef] 
30. Rodegerdts, L.A.; Blogg, M.; Wemple, E.; Myers, E.; Kyte, M.; Dixon, M.; List, G.; Flannery, A.; Troutbeck, R.; Brilon, W.; et al. Roundabouts in the United States; NCHRP Report 572; Transportation Research Board: Washington, DC, USA, 2007.

31. Rodegerdts, L.A.; Malinge, A.; Marnell, P.S.; Beaird, S.G.; Kittelson, M.J.; Mereszczak, Y.S. Accelerating Roundabout Implementation in the United States: Volume I of VII-Assessment of Roundabout Capacity Models for the Highway Capacity Manual; FHWA-SA-15-070; Federal Highway Administration: Washington, DC, USA, 2015.

32. Benjamin, J.R.; Cornell, C.A. Probability, Statistics, and Decision for Civil Engineers; McGraw-Hill: New York, NY, USA, 2014.

33. Smith, G.N. Probability and Statistics in Civil Engineering: An Introduction; Nichols Pub. Co.: New York, NY, USA, 1986.

34. Haukaas, T. Mean-Value First-Order Second-Moment Method (MVFOSM); University of British Columbia: Vancouver, BC, Canada, 2014.

35. Easa, S.M. Design guidelines for symmetrical single-lane roundabouts based on intersection sight distance. J. Transp. Eng. Part A Syst. 2017, 143, 04017052. [CrossRef]

(C) 2020 by the authors. Licensee MDPI, Basel, Switzerland. This article is an open access article distributed under the terms and conditions of the Creative Commons Attribution (CC BY) license (http://creativecommons.org/licenses/by/4.0/). 